\title{
CARTAS, SOLIDÃO E VOZ PARA UMA PÓS-MEMÓRIA: MAREMOTO, DE DJAIMILIA PEREIRA DE ALMEIDA
}

\author{
LETTERS, SOLITUDE AND VOICE FOR A \\ POST-MEMORY: MAREMOTO OF \\ DJAIMILIA PEREIRA DE ALMEIDA
}

Sheila Khan ${ }^{1}$

\section{RESUMO}

O presente artigo procura olhar para dentro do ato de criação de uma pós-memória partindo da análise do romance Maremoto, de Djaimilia Pereira de Almeida. Recolhendo as contribuições teóricas da sociologia das ausências (SANTOS, 2002) e da sociologia pós-colonial das ausências (KHAN, 2015), defende-se as seguintes teses: em primeiro lugar, que o pós-colonialismo de experiência portuguesa encerra em si muitos dos legados de silenciamento e de invisibilização do 'Outro', como no tempo colonial; e, em segundo lugar, a preparação de um chão para a pós-memória implica um compromisso solitário de dever de memória por aqueles que, tanto no passado quanto no presente, se sentem ausentes e silenciados, quer nas narrativas oficiais, quer na arena pública da pós-colonialidade portuguesa.

PALAVRAS-CHAVE: Pós-colonialismo; memória; pós-memória; testemunho; solidão 


\section{ABSTRACT}

This article seeks to look into the act of creating a post-memory based on the analysis of the novel Maremoto, of Djaimilia Pereira de Almeida. Collecting the theoretical contributions from the sociology of absences (SANTOS, 2002) and from the post-colonial sociology of absences (KHAN, 2015), the following theses are defended: first, that the post-colonialism of Portuguese experience contains many of the silencing and invisibility legacies of the 'Other', as in colonial times; and, secondly, the preparation of a ground for post-memory implies a lonely commitment to a duty of memory by those who, in the past as in the present, feel absent and silenced, both in official narratives and in the public arena of Portuguese post-coloniality.

KEYWORDS: Post-colonialism; memory; post-memory; testimony; solitude

\section{PORTUGAL DAS AUSÊNCIAS}

Apesar do seu percurso ainda jovem e recente como escritora e ensaísta, Djaimilia Pereira de Almeida vem contribuindo com os seus vários romances, entre os quais destacamos Esse Cabelo (2015), Luanda, Lisboa, Paraíso (2018), com uma matriz em que literatura, memória e história se concentram cuidadosamente no diálogo sobre identidade, passado colonial, presente pós-colonial, solidão, invisibilidade, testemunho, arte e vida.

O seu recente romance, Maremoto (2021), conduz o leitor por um lugar de escrita madura, depurada, fixa no entendimento de que os tempos da história oficial não escrevem e nem traduzem, com fidelidade e reconhecimento, as narrativas e percursos de todos aqueles sujeitos - homens, mulheres e crianças - que fazem parte de uma longa historicidade de experiência portuguesa africana. Com um olhar literário da realidade histórica deste Portugal pós-colonial, Djaimilia Pereira vai mapeando, a partir das suas personagens, uma partitura de veios, tecidos, detalhes e retalhos de uma outra pele por debaixo dessa grande retórica que é e que tem sido a ideia de um Portugal multicultural, inclusivo e cosmopolita (KHAN, 2015). $\mathrm{Na}$ sua disciplina de análise, reverbera uma metodologia de caracterização dos percursos e contextos sociais e identitários de seus personagens, bem como da desocultação de vários mecanismos e lógicas remanescentes da colonialidade portuguesa, mediante a sua transformação como pós-colonial.

Por exemplo, Luanda, Lisboa, Paraíso (2018) é, com sagacidade histórica, um romance sobre a solidão pós-colonial (KHAN, 2021), o processo silencioso e gradual sobre como o 'Outro' vai, socialmente, se tornando marginal e sendo afastado para uma margem, que não é apenas uma periferia. Esse lugar periférico é muito mais do que um espaço secundário, pois é uma cartografia de um outro lado abissal de espólio humano, que leva o sujeito a se a tornar órfão, fantasmagórico, imperceptível aos olhos de uma combinação de fatores históricos, sociais, econômicos e culturais, que não veem no 'Outro’ um semelhante, pelo contrário, enxerga-o como uma prótese, uma rasura necessária. 
Num momento digno de nota, em Luanda, Lisboa, Paraíso, Djaimilia escreve o apogeu de uma solidão e de um sentimento de abandono que engole os personagens, expulsados de um exterior público para dentro de uma interioridade que os torna residuais e inexistentes:

Ainda antes de perderem tudo, Cartola e Aquiles estavam longe de saber a razão de terem vindo parar à Quinta do Paraíso. A história empurrou-os para uma margem sem que dessem conta de que tinham chegado a terra. Postos de parte, não tinham nem a dignidade dos espoliados nem a honradez redentora dos desgraçados. Tinham apenas o heroísmo insuspeito de terem ficado de lado, como ervas daninhas, querubins, migalhas de pão, e a graça de se poderem reerguer fora do campo de visão de quem os soubesse existentes, enquanto clandestinos não para os mestres de certidões, antes dissimulados no lugar escuro onde os narradores não chegam nem para se regozijarem do facto de terem visto o que mais ninguém viu nem para dizerem que ninguém lá entra. Aquiles e o pai estavam protegidos pela bruma que era a sua existência sem documentos. E então podiam dormir descansados sem serem picados pela agulha de quem quisesse roubar-lhes a palavra, indiferente às suas dores e às variações da sua ambivalência (ALMEIDA, 2018, p. 173).

Djaimilia escreve com a magia de uma voz atenta, lúcida e reparadora das ausências e invisibilidades deste Portugal pós-colonial, trazendo para a clarividência da sua obra um pensamento que não é meramente ficcional, mas inspirado na convocação de outros autores, cujos trabalhos já desenvolveram esta reflexão séria e comprometida com as aporias, fissuras e fragilidades dessa grande casa portuguesa pós-colonial. O presente texto manter-se-ia manco sem uma recuperação do trabalho do sociólogo Boaventura de Sousa Santos, no que concerne ao estatuto de teoria fundamental que o autor elevou ao elaborar a matriz da sociologia das ausências, definida por ele da seguinte maneira:

Trata-se de uma investigação que visa demonstrar que o que não existe é, na verdade, activamente produzido como tal, isto é, como uma alternativa não-credível ao que existe. O seu objecto empírico é considerado impossível à luz das ciências sociais convencionais, pelo que a sua simples formulação representa já uma ruptura com elas. O objectivo da sociologia das ausências é transformar objectos impossíveis em possíveis e com base neles transformar as ausências em presenças (SANTOS, 2002, p. 246).

Conscientes da urgência desta vigilância e rigor epistemológico, outros autores têm recuperado e rebatizado a sociologia das ausências, imigrando as suas interpelações ancoradas na experiência do 'Outro' para a pós-colonialidade portuguesa. Na concretização desta vontade analítica, estudos apontam para as diversas fraturas no seio do pós-colonialismo a partir de dados que demonstram o divórcio entre um pós-colonialismo acadêmico e 
um pós-colonialismo do quotidiano. Esta fratura entre realidade e pensamento é apelativa e alerta para a possibilidade de complementar a sociologia das ausências como uma sociologia pós-colonial das ausências (KHAN, 2015). Nesse sentido, partindo de entrevistas a sujeitos oriundos das antigas ex-colônias portuguesas, é perceptível, por um lado, um desconforto cultural e histórico no espaço da interação social entre os 'Outros' da imigração pós-colonial e da descolonização (KHAN, 2009) e a sociedade portuguesa; e, por outro lado, um sentimento de exílio, de desenraizamento e de desencontros na vivência diária em um Portugal supostamente multicultural.

A pobreza de esforços cívicos e de narrativas oficiais e públicas que apostem no reconhecimento histórico e ontológico do 'Outro', na construção da historicidade portuguesa, é gritante e preocupante no que diz respeito aos legados de um certa colonialidade, que para uns é nostálgica e para outros, inquestionável. Paulo de Medeiros escreve e observa sem pudor esta hegemonia histórica sobrevivente nos nossos tempos atuais, ao salientar que:

As análises académicas da condição pós-colonial de Portugal podem parecer evidentes mas na realidade são prova de um esforço intelectual para confrontar modos de pensar e agir tão enraizados através dos séculos que, apesar de nocivos, aparentam ser naturais. Refiro-me tanto à mentalidade imperialista como ao complexo de inferioridade prevalente pelo menos depois do Ultimato britânico de 1890 (mas que tem raízes muito mais profundas). Aliás, seria uma ingenuidade quase criminosa pensar-se que tais mentalidades teriam sido abolidas depois da entrada de Portugal para o espaço da CEE e a sua aparente reconfiguração como pertencendo, de novo, ao centro. Pelo contrário, muito resta ainda por fazer para se poder compreender como a condição pós-colonial é vivida no quotidiano português e não simplesmente concebida nos modelos teóricos dos investigadores (MEDEIROS, 2015, p. 8).

As ausências assumem um som demasiado ruidoso e incomodativo, que importa interpelar, recuperar e problematizar. Para além dos trabalhos de cariz acadêmico, a arte, na amplitude de seu alcance, permite-nos entrar em lugares que de outra maneira o estatuto do real não permite, entre várias das suas dimensões densas e complexas, como a retórica do multiculturalismo, que, por vezes, assume uma máscara que tende a esconder, manipular e obscurecer realidades humanas em constante desassossego, insegurança social, desterro e solidão. Não seria de todo repetitivo dizer que a literatura como ferramenta estética e observadora do real é uma porta luminosa e metafórica, uma espécie de aqueduto por onde silêncio, solidão e orfandade se transformam num coro importante, constituintes de uma matriz feita de testemunhos, de memória e de pós-memória. Na verdade, Patrícia Ferreira, em um recente estudo sobre o sentido de orfandade na literatura portuguesa contemporânea, e com uma análise generosa de várias obras literárias selecionadas, observa: 
O presente estudo analisa a representação do órfão na literatura portuguesa contemporânea, que revisita criticamente o fim do colonialismo português em África e as consequências da descolonização no tecido social português em termos de renegociação identitária. É, assim, inegável que a perda das colónias africanas e as suas repercussões se evidenciem na reconstrução identitária tanto dos antigos colonos (fosse qual fosse a sua condição sociocultural) e dos seus filhos brancos e mestiços quanto dos africanos [...] (FERREIRA, 2021, p. 17).

Djaimilia Pereira vem laboriosamente estendendo esta manta, construindo este chão em que dever de memória, testemunho e recuperação histórica das ausências representam prioridades cívicas, sociais e culturais, no sentido de dar voz e corpo àquilo que é socialmente mantido como não-presente e marginal. Em Maremoto, o mais recente romance da autora, o sentido de um compromisso para com todos aqueles que a gramática pós-colonial rasurou da nossa consciência histórica,assume uma forma expressa de homenagear o esforço de sobrevivência num lugar íntimo e flutuante entre solidão, desespero, angústia e amor. Através da voz de um homem angolano, Boa Morte da Silva, antigo combatente da guerra colonial na Guiné-Bissau, a narrativa sobre o percurso de um ex-combatente que matou, torturou e massacrou os seus semelhantes, em nome da bandeira portuguesa, os seus semelhantes vai sendo revelada, decalcando a cartografia da guerra em uma terra onde ele vive o amor com uma mulher, e do qual nasce uma filha de nome Aurora.

São simultâneos os lençóis do tempo passado e presente desta história: de um lado, a vida sem farol e sem rumo deste homem que, em Portugal, subsiste à custa do trabalho como arrumador de carros, indivíduo que chega à terra pela qual lutou de uma maneira anônima, sem uma mão e rosto para o acolherem; um ex-combatente que traz consigo os traumas da guerra, os pesadelos de violência, morte e sangue que o assolam nas noites solitárias; um cidadão português sem pátria, sem documentos, sem um mapa onde colocar o seu calendário de vida, a sua narrativa, a sua identidade; e, de um outro lado, um marido que agrediu e abandonou a sua mulher; um pai que escreve cartas a uma filha que ele não conhece, de quem não sabe o paradeiro, cerzindo para si um trabalho de memória, um testemunho em busca de empatia, fraternidade e de ternura. As missivas, nesse contexto, vão arquivando, organizando e trazendo voz, corpo e patrimônio para uma pós-memória futura:

[...] teu pai engoliu a morte, Aurora, pela porrada toda que dei nesta vida, por quantos compatriotas matei na guerra sem misericórdia, preto que mata preto tem de sofrer amargamente, minha filha, por mil séculos, fora o resto, por tudo isso. Teu pai está grávido da morte, empanturrado, por isso não tenhas pena, eu não me queixo. A papelada é o meu tabulário de existências, tabulário de senhor Boa Morte da Silva, penso que é assim que se diz, filho de pai incógnito, orgulhoso Cuanhama, cidadão caducado, tabulário para ser lido por 
quem encontre a minha mochila ou por ti, se o Abdul te conseguir localizar e se conseguires ler a letra do teu pai. Me dá um medo de perder a mochila por aí, no metropolitano, nalguma esquina (ALMEIDA, 2021, p. 24) ${ }^{2}$.

\section{CARTAS PARA UMA PÓS-MEMÓRIA FUTURA}

A urgência de mexer nas areias profundas e íntimas da memória do eu e de, a partir das cartas a sua filha, lançar sementes e pontes para uma memória futura representa uma nova leitura e conceptualização do desenvolvimento das dimensões várias e complexas que a pós-memória pode revelar.

Primordialmente, pós-memória foi definida por Marianne Hirsch como um conceito que “(...)aponta para a relação da segunda geração com experiências marcantes, muitas vezes traumáticas, que são anteriores ao seu nascimento, mas que, não obstante, lhes foram transmitidas de modo tão profundo que parecem constituir memórias em si mesmas." (HIRSCH, $2008,103)$. Estudos recentes, com um foco analítico muito atento às relações entre arte e pós-memória, confirmam e sedimentam esta inclinação conceptual. Basta um exame cuidado atento e uma revisão da literatura sobre pós-memória para enriquecermos o nosso conhecimento sobre os avanços atuais neste campo. Trabalhos como os de Margarida Calafate Ribeiro (2020), de António Sousa Ribeiro e Margarida Calafate Ribeiro (2013), de Roberto Vecchi (2020) e de Paulo Medeiros (2020) revelam a pertinência e a solidez dos fundamentos do estudo da pós-memória, baseado no espaço e no tempo dos processos de descolonização - que não se restringe à experiência portuguesa, mas se estende a outros países de experiência colonialista e imperialista -, mostrando com as suas análises a sobrevivência de lógicas e mecanismos de colonialidade estrutural (KHAN, CAN, MACHADO, 2021; KHAN, 2021; KHAN, MACHADO, 2021; JERÓNIMO, MONTEIRO, 2020).

Maremoto abre um novo lugar para pensar e mapear a pós-memória, não apenas através de uma transferência de experiências intrafamiliares, mas a partir de um exercício solitário de constituição de arquivos de memória individual, com o objetivo de lançar sementes para um interesse e atenção, quer da parte de um ser mais próximo, quer de outros indivíduos anônimos: É na revelação deste vazio de acolhimento familiar e público que estas cartas que Maremoto nos convida a ler, e que curiosamente nos desperta para um olhar vigilante e consciente de uma pós-memória em construção, em permanente co-criação. Esta observação dirige-nos para o pensamento de Márcio Seligmann-Silva que, em O Local do testemunho, observa:

Se o "real" pode ser pensado como um "desencontro" (algo que nos escapa como o sobrevivente o demonstra a partir de sua situação radical), não deixa de ser verdade que a linguagem e, sobretudo, a linguagem da poesia e da literatura, busca este encontro impossível. Vendo o testemunho como o vértice entre a história e a memória, entre os "fatos" e as narrativas, entre, em suma, o simbólico e o indivíduo, esta necessidade de um pensamento aberto para a linguagem da poesia no contexto testemunhal fica mais clara (SELIGMANN-SILVA, 2010, p. 6). 
A solidão das testemunhas que Bruno Sena Martins (2015), cuidadosamente, decalca, no seu estudo etnográfico e documental sobre ex-combatentes com deficiência da guerra colonial, atinge, neste romance, um tom de um silêncio maior, brutalmente desértico, de parceiros com quem o personagem possa partilhar os seus traumas, as suas angústias e as suas mágoas, os pesadelos, a violência incrustada no corpo e na memória que vive, em sono, essa mesma violência:

Pesadelo, ontem. Cara na lama, a rastejar no mato. Rastejo, me sinto verme, sem conseguir respirar. Levo o armamento, que pesa para diabo. As botas são dois calhaus. O pior é o mato acima de mim, todo ele é uma mão que me puxa pelos pés, a impedir-me de aguentar o peso nos cotovelos. Mal consigo ver um palmo à minha frente, o capim arranha-me, perdi meu companheiro, o Vítor, há segundos, o pavor de o ter visto morto nos meus braços vai nos meus olhos e dentro do meu peito, Aurora, me sufoca, me esmaga. Vou esmagado pelo mato, os tiros não param, rastejo, sou verme, o chão debaixo da lama me falta, meu amigo morreu no meu colo encostado na palmeira, ainda vejo seus olhos me dizendo que o salve, sua boca em sangue a gemer as últimas palavras, me diz "Joana, vai até à Joana, fica na Cova da Beira, Boa Morte".

E é no passado a rastejar na lama, a fugir ao inimigo, mas sei que não honrei meu alferes, que deu vida por mim (ALMEIDA, 2021, p. 39).

Neste romance, não existe qualquer resquício ou possibilidade de uma "hospitalidade à memória e ao reconhecimento das identidades passíveis de se afirmarem dentro de uma comunidade, numa transformação recursiva entre sujeito e narrativa social” (MARTINS, 2015, p. 113). Pelo contrário, o mais aflitivo não é somente a ausência do eu e do ser perante o olhar dos outros, mas a consciência levada ao limite de uma cegueira social e ontológica perante o ser que vive, que habita e deambula nas ruas e lugares onde outras pessoas respiram e constroem elos de sociabilidade:

[...] sou um homem sem bagagem, filha, um marinheiro sem navio. Minha terra são esses malucos aqui do Chiado, ninguém nos vê pela rua, podemos andar esfarrapados, ninguém nos olha, mas vemo-nos uns aos outros, vivemos aí, na transparência, a trocar conversa, trocar pão, trocar vinho, espíritos do além, que andam por Lisboa (...). (...) somos os guardiões das ruas, (...), patrões do estacionamento dão-me moeda todo o santo dia sem me perguntar sequer meu nome, nem vêem a minha mão, pagam na mão do espírito para lhes poupar à morte, pagam para eu não dar chatice. Ia escrever agora, minha filha, enterrados em vida, eu e os meus amigos aqui do Chiado. Agora, somos espíritos que habitam as ruas, a andar com os pés e as pernas, a falar e a respirar, mas as pessoas passam, circulam e não nos vêem (ALMEIDA, 2021, p. 15). 
Um cenário sócio-cultural profundamente marcado por um défice de vontade histórica de acolher, conhecer, decifrar o 'Outro' na sua diferença, mas, simultaneamente, no que esse 'Outro' tem de mais próximo, similar e umbilical com a historicidade seja colonial, seja pós-colonial da experiência portuguesa, que vemos transbordar sem pudor e ferozmente em cada partícula humana de solidão em Boa-Morte da Silva:

Portugal, como te explicar a ti que essa é minha terra, filha, sem ferir o teu coração? Terra de um homem é a terra que ele cava, terra pela qual um homem mata, e eu matei por Portugal antes de conhecer as ruas de Lisboa.

Olhos dos homens a quem tirei a vida, o seu sangue nas minhas mãos, a compaixão que por eles não senti, sangue que verti, juramento às cegas pela minha pátria nunca pisada. Atrás dum homem veio outro e outro. Portugal cresceu em mim dentro do mato, razão da minha jura.

Caminho cidadão pleno, mesmo que me tomem por vagabundo. Meus compatriotas, tua mãe, para eles sou, talvez, traidor. Se sou traidor, é como um homem que jurou morrer para salvar seu velho pai. À minha chegada, meu pai me abriu a porta, mas não me reconheceu (ALMEIDA, 2021, p. 67³).

A importância da memória permanece ativa e densamente implicada na presentificação da história e, aqui, recorremos ao pensamento de António Sousa Ribeiro, quando, ao analisar todo o mecanismo de elevação da testemunha e do testemunho no espaço de uma reflexão séria e comprometida sobre o Holocausto, observa: "[...] muito mais do que o trabalho da história, é o trabalho da memória que desempenha um papel decisivo" (RIBEIRO, 2010, p. 11). Neste percurso solitário de exposição de uma memória pessoal, lê-se e sente-se a inexistência de estímulos sociais e culturais que poderiam ajudar nesta partilha testemunhal, representando as cartas que Boa Morte da Silva escreve a sua filha Aurora um arquivo humano, uma ferramenta rica para o estudo e reflexão de outras memórias que possam enriquecer e complementar, desse modo, as visões hegemónicas e oficiais da historicidade portuguesa, quer do Ultramar, do contexto das guerras colonial e de libertação, quer do dealbar das múltiplas cartografias de emancipação e de descolonização.

Com determinação, estudos de cariz interdisciplinar têm aberto esse caminho para a necessidade de uma riqueza epistemológica que recomponha e reorganize o puzzle histórico da sociedade portuguesa com outras vozes, narrativas e percepções (KHAN, 2015; MARTINS, MOURA, 2018), colmatando, desse modo, ausências, vigiando novos caminhos de investigação, por sua vez mais atentos para uma cidadania da reparação e da recuperação histórica da ausência do 'Outro'. 


\section{REFLEXÃO FINAL: PARA UMA CIDADANIA DAS AUSÊNCIAS}

Maremoto conduz-nos pelos vários caminhos íntimos, profundos e densos da vida e da identidade do seu personagem, através da solidão e ausência abissais de que padece a pós-colonialidade portuguesa. A ausência pós-colonial foi, neste texto, analisada e decalcada não apenas para uma leitura enriquecedora sobre os processos de identificação pós-colonial, mas também para levar mais longe esta reflexão, passando pelo seu impacto moral, social e histórico, isto é, pela pertinência domapeamento crítico das ausências pós-coloniais. Dessa forma, colocamos tais considerações em um patamar que possa educar historicamente a nossa consciência, sensibilidade e cultura da memória perante o 'Outro'. Em outro trabalho, Khan observa que:

[...] O Portugal que se imagina de pós-colonial não pode mais escrever-se e retratar-se sem o reconhecimento das diversas aprendizagens que a sua historicidade foi produzindo e sem os périplos que foram calcorreados por todos aqueles que viveram, testemunharam e são, hoje, legitimamente sujeitos herdeiros dessas suas trajectórias culturais e sociais. O puzzle só se completará com a força e o fulgor de outras vozes, que apesar de omitidas e esquecidas no tecido pós-colonial português, permanecem longe de um olhar que as possa assumir e validar como portadoras de outras formas de pensar, analisar e mensurar o que é, actualmente, o estado da vivência da pós-colonialidade portuguesa (KHAN, 2015, p. 119).

Saímos da leitura deste romance conscientes de que a perpetuação de uma memória resulta necessariamente de um esforço e de uma disciplina subjectivas, que almeja dar um sentido de continuidade ao acervo de uma vida que, aos olhos da história oficial portuguesa, permanece totalmente inexistente, marginal e superlativamente residual. Por conseguinte, a possível lição que Maremoto nos inspira é simples e clara: mais do que depender de um interesse público e geracional, a preservação de uma memória depende fortemente de um gesto e de uma abertura subjetiva de fraternidade, empatia e de partilha mais individual do que coletiva.

Se a pergunta tão sabiamente colocada sobre a "quem pertence Auschwitz?" (RIBEIRO, 2010, p. 14) dependia da resposta enérgica de uma nova vivência geracional posterior àquela que viveu direta ou indiretamente aquele acontecimento trágico e hediondo, Djaimilia Pereira viu e intuiu um outro caminho, uma nova resolução, para dar uma renovada clarividência élan na pós-colonialidade portuguesa. Disto isto, inferimos que essas considerações confluem com as de quem esteja preparado para entrar, desfrutar e habitar ativamente estes elos de continuidade, com a consciência de encetar um caminho onde memória, herança, presença e cidadania estarão ativamente de mãos dadas em prol de uma reparação das ausências pós-coloniais. Por isso, são magistrais as linhas que Boa Morte da Silva escreve a sua filha Aurora que, metaforicamente, representa o tempo futuro para uma pós-memória em co-criação: "Aurora, queria ouvir tua voz, escutar as tuas palavras e ver os teus olhos, estar vivo ao teu lado, respirar como tu" (ALMEIDA, 2021, p. 12). 


\section{REFERÊNCIAS}

ALMEIDA, Djaimilia Pereira. Esse Cabelo. Lisboa: Teorema, 2015.

ALMEIDA, Djaimilia Pereira. Luanda, Lisboa, Paraíso. Brasil: Companhia das Letras, 2018.

ALMEIDA, Djaimilia Pereira. Maremoto. Lisboa: Relógio D’Água, 2021.

FERREIRA, Patrícia Martinho. Órfãos do Império. Heranças Coloniais na Literatura Portuguesa Contemporânea. Lisboa: ICS, Imprensa de Ciências Sociais, 2021.

HIRSCH, Marianne. The generation of postmemory. Poetics Today, 29(1), p. 103-28, 2008. Disponível em: https://read.dukeupress.edu/poetics-today/ article/29/1/103/20954/The-Generation-of-Postmemory. Acesso em: 31 mai. 2021. DOI: 10.1215/03335372-2007-019.

JERÓNIMO, Miguel Bandeira; MONTEIRO, José Pedro. Histórias do Presente. Os mundos que o passado nos deixou. Lisboa: Tinta-da-China, 2020.

KHAN, Sheila. Imigrantes Africanos Moçambicanos. Narrativa de Imigração e de Identidade e Estratégias de Aculturação em Portugal e na Inglaterra. Lisboa: Editora Colibri, 2009.

KHAN, Sheila. Portugal a lápis de cor. A Sul de uma pós-colonialidade. Coimbra: Almedina, 2015.

KHAN, Sheila. A Alquimia dos Mecanismos de Racialização, Criminalização e Vigilância RaciaL. In: MACHADO, Helena (ed.), Crime e Tecnologia: Desafios Culturais e Políticos para a Europa. Porto: Afrontamento, 2021, no prelo.

KHAN, Sheila; MACHADO, Helena. Postcolonial Racial Surveillance through Forensic Genetics. In: KHAN, Sheila; CAN, Nazir; MACHADO, Helena (eds.), Racism and Racial Surveillance. London: Routledge, 2021, no prelo.

MARTINS, Bruno Sena; MOURA, Adriano. Portugal e década internacional de afrodescendentes: a educação e os tempos da violência colonial. Educação em Revista, vol.34, p.1-23, 2018. Disponível em: https://estudogeral.sib.uc.pt/ bitstream/10316/81697/1/Portugal\%20e\%20decada\%20internacional\%20 de\%20afrodescendentes.pdf. Acesso em 17 mai. 2021. DOI: 10.1590/01024698192750 .

MARTINS, Bruno Sena. Violência colonial e testemunho: Para uma memória pós-abissal. Revista Crítica de Ciências Sociais, n.106, p. 105-126, 2015. Disponível em: https://journals.openedition.org/rccs/5904. Acesso em 17 mai. 2021. DOI: $10.4000 /$ rccs.5904.

MEDEIROS, Paulo de. Memórias Pós-imperiais: Luuanda, de José Luandino Vieira, e Luanda, Lisboa, Paraíso, de Djaimilia Pereira de Almeida. Revista Língua-lugar: Literatura, História, Estudos Culturais, n.1, p. 136.149, 2020. Disponível em: https://estudogeral.sib.uc.pt/bitstream/10316/90230/1/Memorias\%20pos-imperiais.pdf. Acesso em: 20 mai. 2021. DOI: 10.34913/ journals/lingua-lugar.2020.e211 
MEDEIROS, Paulo de. No fio da navalha. In: KHAN, Sheila. Portugal a lápis de cor. A Sul de uma pós-colonialidade. Coimbra: Almedina, 2015, p. 7-13.

RIBEIRO, António Sousa. Memória, identidade e representação: Os limites da teoria e a construção do testemunho. Revista Crítica em Ciências Sociais, n.88, p. 9-21, 2010. Disponível em: https://journals.openedition.org/rccs/1748. Acesso em 17 mai. 2021. DOI: 10.4000/rccs. 1748

RIBEIRO, Margarida Calafate; RIBEIRO, António Sousa Ribeiro. Os netos que Salazar não teve: Guerra Colonial e memória de segunda geração. ABRIL - Revista do Núcleo de Estudos de Literatura Portuguesa e Africana da UFF, vol. 5, n 11, Novembro, p.25-36, 2013. Disponível em:https://estudogeral.sib. uc.pt/bitstream/10316/43865/1/Os\%20Netos\%20que\%20Salazar\%20não\%20 teve.pdf. Acesso em: 20 maio 2021. DOI: 10.22409/abriluff.2013n11a43.

RIBEIRO, Margarida Calafate. Arte e Pós-memória - fragmentos, fantasmas, fantasias. Diacrítica, vol.34, n.2, p.4-20, 2020. Disponível em:

https://estudogeral.sib.uc.pt/bitstream/10316/90496/1/Arte\%20e\%20Pos\%20 Memoria.pdf. Acesso em: 20 mai. 2021. DOI: doi.org/10.21814/diacritica.523.

SANTOS, Boaventura de Sousa. Para uma sociologia das ausências e uma sociologia das emergências. Revista Crítica em Ciências Sociais, n.23, Outubro, p.237-280, 2002. Disponível em:

http://www.boaventuradesousasantos.pt/media/pdfs/Sociologia_das_ausencias_RCCS63.PDF. Acesso em 17 mai. 2021. DOI: 10.4000/rccs.1285

SELIGMANN-SILVA, Márcio.O local do testemunho. Tempo e Argumento, v.2, n.1, p.3-20, 2010. Disponível em: https://www.redalyc.org/ pdf/3381/338130372002.pdf. Acesso em 17 mai. 2021. E-ISSN: 2175-1803

VECCHI, Roberto. A nostalgia colonial no País da saudade: fantasmagorias e pós-memória. Confluenze. Rivista di Studi Iberoamericani, vol.12, n.2, p.169-181, 2020. Disponível em:https:/estudogeral.sib.uc.pt/ bitstream/10316/92782/1/A\%20nostalgia\%20colonial\%20no\%20Pais\%20 da\%20saudade.pdf. Acesso em: 21 mai. 2021. DOI: 10.6092/issn.20360967/1217.

Recebido para avaliação em 31/05/2021 Aprovado para publicação em 12/06/2021

\section{NOTAS}

1 Sheila Khan é socióloga, investigadora do Centro de Estudos em Comunicação e Sociedade (CECS) da Universidade do Minho. Doutorada em Estudos Étnicos e Culturais pela Universidade de Warwick. As suas mais recentes publicações são: "Portugal a lápis de cor. A sul de uma pós-colonialidade" (Almedina, 2015); "Visitas a João Paulo Borges Coelho. Leituras, Diálogos e Futuros" (com Nazir Can, Sandra Sousa, Leonor Simas-Almeida e Isabel Ferreira Gould, Colibri, 2017); "A Europa no Mundo, o Mundo na Europa. Crise e Identidade" (com Rita Ribeiro e Vítor Sousa, Editora Húmus, 2020); e, "Racism and Racial Surveillance. Modernity Matters" (com Nazir Can e Helena Machado, London: Routledge, 2021).

2 Grifo do autor.

3 Grifo do autor. 